\title{
Synthesis, Characterization, and Physicochemical Studies of Mixed Ligand Complexes of Inner Transition Metals with Lansoprazole and Cytosine
}

\author{
Sarika Verma, Sarita Shrivastva, and Rashmi Shrivastva \\ Chemical Laboratory, Government Motilal Vigyan Mahavidhalaya, Bhopal, India \\ Correspondence should be addressed to Sarika Verma, sarikaverma2009@gmail.com.
}

Received 29 January 2012; Revised 11 July 2012; Accepted 13 July 2012

Academic Editor: Artur Silva

Copyright (C) 2013 Sarika Verma et al. This is an open access article distributed under the Creative Commons Attribution License, which permits unrestricted use, distribution, and reproduction in any medium, provided the original work is properly cited.

\begin{abstract}
Few complexes of inner transition metals [Th(IV), Ce(IV), Nd(III), Gd(III)] have been synthesized by reacting their metal salts with lansoprazole, 2-([3-methyl-4-(2,2,2-trifluoroethoxy)pyridin-2-yl]methylsulfinyl)- $1 H$-benzoimidazole and cytosine. All the complexes were synthesized in ethanolic medium. The yield percentage rangs from 80 to $90 \%$. The complexes are coloured solids. The complexes were characterized through elemental analyses, conductance measurements, and spectroscopic methods (FT IR, FAB Mass, ${ }^{1} \mathrm{H}$ NMR and UV). An IR spectrum indicates that the ligand behaves as bidentate ligands. The metal complexes have been screened for their antifungal activity towards Aspergillus niger fungi. The interaction of inner transition metals with lansoprazole, in presence of cytosine, has also been investigated potentiometrically at two different temperatures $26 \pm 1^{\circ} \mathrm{C}$ and $36 \pm 1^{\circ} \mathrm{C}$ and at $0.1 \mathrm{M}\left(\mathrm{KNO}_{3}\right)$ ionic strength. The stability constants of ternary complexes indicate the stability order as Th(IV) $<\mathrm{Ce}(\mathrm{IV})<\mathrm{Gd}(\mathrm{III})$ $<\mathrm{Nd}(\mathrm{III})$. $\log K$ values obtained are positive and suggest greater stabilization of ternary complexes. The values of thermodynamic parameters (free energy $(\Delta G)$, enthalpy $(\Delta H)$, and entropy $(\Delta S)$ are also calculated.
\end{abstract}

\section{Introduction}

Inner transition metal complexes are of continuing interest mainly due to their structural and catalytical properties and their application in diagnostic pharmaceutical and laser technology [1-3]. They have been found to exhibit anticancer and fungicidal properties also [4].

Investigations are going on the formation of metal complexes with benzimidazole ring containing ligands because benzimidazole and its derivatives play an important role in analysis and in several biological reactions [5]. Considering the importance of drugs and their complexes it has been desired to synthesize and characterize some ternary complexes of inner transition metal [Th(IV), Ce(IV), Gd(III), $\mathrm{Nd}(\mathrm{III})$ ] with a Benzimidazole derivative, lansoprazole, and cytosine. Lansoprazole being an antiulcer drug reduces gastric acid secretion and has successfully been used to heal and relieve symptoms of gastric or duodenal ulcers and gastroesophageal reflux [6-9].

As the interaction of metal ions with nucleobases is of great interest because of their relevance to the essential, medical or toxic bioactivity of metal, where nucleobase molecule can coordinate as exogenous ligands in metalloproteins, function as cofactors in the enzymatic systems. Thus, cytosine is selected as the secondary ligand for the formation of ternary complexes. Its chemical name is 4 -amino- $1 \mathrm{H}$ pyrimidine- 2 one [10].

\section{Experimental}

All the chemicals used throughout the course of experiments were either of BDH or E merck quality. Spectroscopic grade solvents were employed for recording the spectra.

2.1. Preparation of the Complexes. The solid complexes were prepared by mixing the aqueous solution of metal salts $\left[\mathrm{Th}\left(\mathrm{NO}_{3}\right)_{4} \cdot 4 \mathrm{H}_{2} \mathrm{O}, \mathrm{Ce}\left(\mathrm{SO}_{4}\right)_{2} \cdot x \mathrm{H}_{2} \mathrm{O}, \mathrm{Nd}\left(\mathrm{NO}_{3}\right)_{3} \cdot 6 \mathrm{H}_{2} \mathrm{O}\right.$, $\mathrm{Gd}\left(\mathrm{NO}_{3}\right)_{3} \cdot 6 \mathrm{H}_{2} \mathrm{O}$ ] with ethanolic solution of lansoprazole and cytosine in molar ratio $1: 1: 1$. The resulting mixtures were then refluxed for 4-5 hours to give the precipitate. After cooling at room temperature the solid complexes were filtered as fine precipitates. These precipitates were washed 
TABLE 1: Stability constants of ternary complexes of Lanso (L) and Cyto (C) at $26 \pm 1^{\circ} \mathrm{C}$ and $36 \pm 1^{\circ} \mathrm{C}$.

\begin{tabular}{lcc}
\hline Metal complexes & & $\log K_{\mathrm{MLC}}^{\mathrm{M}}$ \\
\hline $\mathrm{Th}$ & At temp. $26 \pm 1^{\circ} \mathrm{C}$ & $36 \pm 1^{\circ} \mathrm{C}$ \\
$\mathrm{Ce}$ & 5.50 & 5.35 \\
$\mathrm{Gd}$ & 6.5 & 6.4 \\
$\mathrm{Nd}$ & 7.5 & 7.1 \\
\hline
\end{tabular}

TABLE 2: Ligation free energy, enthalpy, and entropy change of mixed ligand complexes of M-Lanso-Cyto at $26 \pm 1^{\circ} \mathrm{C}$ and $36 \pm 1^{\circ} \mathrm{C}$ and at $\mu=0.1 \mathrm{~m}\left(\mathrm{KNO}_{3}\right)$.

\begin{tabular}{|c|c|c|c|c|c|c|}
\hline \multirow{2}{*}{ Metal complexes } & \multicolumn{2}{|c|}{$-\Delta G(\mathrm{~K} \cdot \mathrm{cal} . / \mathrm{mole})$} & \multicolumn{2}{|c|}{$-\Delta H(\mathrm{~K} \cdot \mathrm{cal} . / \mathrm{mole})$} & \multicolumn{2}{|c|}{$-\Delta S(\mathrm{~K} \cdot \mathrm{cal} . / \mathrm{mole})$} \\
\hline & $26 \pm 1^{\circ} \mathrm{C}$ & $36 \pm 1^{\circ} \mathrm{C}$ & $26 \pm 1^{\circ} \mathrm{C}$ & $36 \pm 1^{\circ} \mathrm{C}$ & $26 \pm 1^{\circ} \mathrm{C}$ & $36 \pm 1^{\circ} \mathrm{C}$ \\
\hline$\left[\right.$ Th. Lanso $\cdot$ Cyto $\left.\cdot 4 \mathrm{H}_{2} \mathrm{O}\right] \mathrm{NO}_{3} \cdot x \mathrm{H}_{2} \mathrm{O}$ & 1.012 & 1.029 & 313.01 & 307.93 & 31.19 & 30.69 \\
\hline$\left[\right.$ Ce-Lanso $\cdot$ Cyto $\left.4 \mathrm{H}_{2} \mathrm{O}\right] \mathrm{SO}_{4} \cdot x \mathrm{H}_{2} \mathrm{O}$ & 1.112 & 1.139 & 343.68 & 340.83 & 34.25 & 33.96 \\
\hline$\left[\mathrm{Gd} \cdot\right.$ Lanso $\cdot$ Cyto $\left.4 \mathrm{H}_{2} \mathrm{O}\right] \mathrm{NO}_{3} \cdot x \mathrm{H}_{2} \mathrm{O}$ & 1.197 & 1.203 & 369.95 & 359.89 & 36.87 & 35.86 \\
\hline$\left[\mathrm{Nd} \cdot\right.$ Lanso $\cdot$ Cyto $\left.4 \mathrm{H}_{2} \mathrm{O}\right] \mathrm{NO}_{3} \cdot x \mathrm{H}_{2} \mathrm{O}$ & 1.257 & 1.284 & 388.568 & 384.090 & 38.73 & 38.28 \\
\hline
\end{tabular}

twice with water. Then they were dried and stored in a desiccators containing dry calcium chloride. The compounds obtained were stable coloured solids.

2.2. Physical Measurement. The melting point was recorded on Labotech instrument. Elemental analysis was performed on a Carlo Erba mod 1108 elemental analyzer. The Mass spectra was done on a Jeol SX-102 spectrometer using argon as the FAB gas Elico and SL191 double beam uv-vis spectrophotometer is used for recording uv-vis spectra. The ${ }^{1} \mathrm{H}$ NMR spectra were recorded on Bruker DRX-300. The FT IR spectrum was recorded on Varian 1000 FTIR using KBR Pallets. The antifungal activity is studied by paper disk method and data was recorded after 48 hours of incubation.

2.2.1. Ligand-Metal Ratio. The metal-ligand-ligand ratio was confirmed by conductometric titration method.

2.2.2. Stability of Complexes. Stepwise and overall proton ligand stability constants were computed by Bjerrum clavin $\mathrm{pH}$ titration technique as adapted by Irving and Rossotti. The extension of this titration technique to ternary system, as suggested by Chidambaram and Bhattacharya [11] has been applied to determine the stability constants of $1: 1: 1$ ternary complexes at $26 \pm 1^{\circ} \mathrm{C}$ and $36 \pm 1^{\circ} \mathrm{C}$.

The proton ligand stability constant of the drug lansoprazole and cytosine has been calculated at $26 \pm 1^{\circ} \mathrm{C}$ and $36 \pm 1{ }^{\circ} \mathrm{C}$ and at $0.1 \mathrm{M}\left(\mathrm{KNO}_{3}\right)$ ionic concentration, utilizing the Irving Rossotti pH titration technique [12].

2.3. Thermodynamic Parameters. Thermodynamic parameters computed for the complexation reactions studied in this investigation are free energy $(\Delta G)$, enthalpy $(\Delta H)$, and entropy $(\Delta S)$ changes [13].

The reaction will go in the direction written, when $\Delta G$ is negative. These have been calculated using the Vant Hoff isotherm, Vant Hoff equation, and the Gibbs-Helmholtz equations, respectively, at $26^{\circ} \mathrm{C}$ and $36^{\circ} \mathrm{C}$ and at ionic strength of $0.1 \mathrm{M}$ with $\mathrm{KNO}_{3}$ :

$$
\begin{gathered}
\Delta G=-2.303 R T \log _{10} K, \\
\Delta H=4.576 \frac{T_{1} \times T_{2}}{T_{2}-T_{1}} \log _{10} K \\
\Delta S=\frac{\Delta H-\Delta G}{\Delta T} .
\end{gathered}
$$

\section{Result and Discussion}

3.1. Stability of Complexes. The $\Delta \log K$ values obtained in the present study (recorded in Table 1) are positive indicating greater stabilization (greater degree of chelation) of ternary complexes.

The stability order obtained in the present investigation is shown below:

\section{(M-LANSO-CYTO)}

$$
\begin{array}{ll}
\mathrm{Th}<\mathrm{Ce}<\mathrm{Gd}<\mathrm{Nd} & \text { at } 26 \pm 1^{\circ} \mathrm{C}, \\
\mathrm{Th}<\mathrm{Ce}<\mathrm{Gd}<\mathrm{Nd} & \text { at } 36 \pm 1^{\circ} \mathrm{C} .
\end{array}
$$

3.2. Thermodynamic Parameters. The values of changes in free energy $(\Delta G)$, enthalpy $(\Delta H)$, and entropy $(\Delta S)$ recorded in Table 2, accompanying the formations of the ternary complexes, using the standard equations are as in [14]. The negative values of $\Delta G$ show that the driving tendency of the complexation reaction is from left to right and the reaction tends to proceed spontaneously.

\section{Analytical Data of Complexes}

The reaction of the inner transition metal with lansoprazole and cytosine was afforded in good yield (85-90\%) of stable solid compound. The compounds prepared were coloured, soluble in ethanol, 1, 4 dioxane, DMF, DMSO and 
TABLe 3: Analytical data of synthesized mixed ligand complexes of M-Lanso-Cyto.

\begin{tabular}{|c|c|c|c|c|}
\hline Serial no. & Complex & Color & Melting point & Molar conductance $\left({ }^{\wedge} / \mathrm{S} \mathrm{cm}^{2} \mathrm{~mol}^{-1}\right)$ \\
\hline 1 & {$\left[\right.$ Th. Lanso $\cdot$ Cyto $\left.\cdot 4 \mathrm{H}_{2} \mathrm{O}\right] \mathrm{NO}_{3} \cdot x \mathrm{H}_{2} \mathrm{O}$} & Light brown & $322^{\circ} \mathrm{C}$ & 96.1 \\
\hline 2 & [Ce.Lanso $\cdot$ Cyto $\left.\cdot 4 \mathrm{H}_{2} \mathrm{O}\right] \mathrm{SO}_{4} \cdot x \mathrm{H}_{2} \mathrm{O}$ & Light brown & $319^{\circ} \mathrm{C}$ & 89.6 \\
\hline 3 & {$\left[\mathrm{Gd} \cdot\right.$ Lanso $\cdot$ Cyto $\left.\cdot 4 \mathrm{H}_{2} \mathrm{O}\right] \mathrm{NO}_{3} \cdot x \mathrm{H}_{2} \mathrm{O}$} & Orange & $300^{\circ} \mathrm{C}$ & 94.2 \\
\hline 4 & {$\left[\mathrm{Nd} \cdot\right.$ Lanso $\cdot$ Cyto $\left.\cdot 4 \mathrm{H}_{2} \mathrm{O}\right] \mathrm{NO}_{3} \cdot x \mathrm{H}_{2} \mathrm{O}$} & Black & $320^{\circ} \mathrm{C}$ & 80.2 \\
\hline 5 & {$\left[\mathrm{Sm} \cdot\right.$ Lanso $\cdot$ Cyto $\left.\cdot 4 \mathrm{H}_{2} \mathrm{O}\right] \mathrm{NO}_{3} \cdot x \mathrm{H}_{2} \mathrm{O}$} & Black & $319^{\circ} \mathrm{C}$ & 79.2 \\
\hline 6 & {$\left[\right.$ Ytt.Lanso $\cdot$ Cyto $\left.\cdot 4 \mathrm{H}_{2} \mathrm{O}\right] \mathrm{NO}_{3} \cdot x \mathrm{H}_{2} \mathrm{O}$} & Black & $315^{\circ} \mathrm{C}$ & 83.2 \\
\hline
\end{tabular}

TABLE 4: Elemental analysis of mixed ligand complexes of Lanso and Cyto.

\begin{tabular}{|c|c|c|c|c|c|c|c|}
\hline \multirow{2}{*}{ Metal complex } & \multicolumn{7}{|c|}{ Found mass (calculated mass \%) } \\
\hline & $\mathrm{C}$ & $\mathrm{H}$ & $\mathrm{N}$ & $\mathrm{O}$ & $\mathrm{F}$ & S & Metal \\
\hline [Th.Lanso $\cdot$ Cy to $\left.4 \mathrm{H}_{2} \mathrm{O}\right] \mathrm{NO}_{3} \cdot x \mathrm{H}_{2} \mathrm{O}$ & $30.26(30.6)$ & $3.4(3.4)$ & $10.59(10.71)$ & $12.1(12.24)$ & $7.18(7.27)$ & $4.03(4.08)$ & $32.44(31.65)$ \\
\hline$\left[\right.$ Ce. Lanso $\cdot$ Cyto $\left.4 \mathrm{H}_{2} \mathrm{O}\right] \mathrm{SO}_{4} \cdot x \mathrm{H}_{2} \mathrm{O}$ & $33.99(34.6)$ & $3.82(3.9)$ & $11.89(12.13)$ & $13.59(13.5)$ & $8.07(8.23)$ & $4.53(4.64)$ & $24.11(22.55)$ \\
\hline$\left[\mathrm{Gd} \cdot\right.$ Lanso $\cdot$ Cyto $\left.\cdot 4 \mathrm{H}_{2} \mathrm{O}\right] \mathrm{NO}_{3} \cdot x \mathrm{H}_{2} \mathrm{O}$ & $34.13(33.8)$ & $3.84(3.8)$ & $11.94(11.8)$ & $13.65(3.54)$ & $8.1(8.0)$ & $4.55(4.51)$ & $23.79(24.4)$ \\
\hline$\left[\mathrm{Nd} \cdot\right.$ Lanso $\cdot$ Cyto $\left.\cdot 4 \mathrm{H}_{2} \mathrm{O}\right] \mathrm{NO}_{3} \cdot x \mathrm{H}_{2} \mathrm{O}$ & $34.23(34.4)$ & $3.85(3.87)$ & $11.98(12.06)$ & $13.69(13.7)$ & $8.13(8.1)$ & $4.56(4.5)$ & $23.56(23.03)$ \\
\hline
\end{tabular}

insoluble in water. The characterization of their molecular structure was made by elemental analysers conductivity and spectroscopy studies. The studied complexes of inner transition metal showed $1: 1: 1$ (M:LANSO:CYTO) composition as indicated from elemental analyser and exhibited corresponding conductivities suggesting 1:1:1 electrolytic behaviour. The analytical data including yield percentage of the complexes are recorded in Table 3.

\section{Elemental Analysis}

The result of elemental analysis is recorded in Table 4.

5.1. FT IR Spectra. The relevant vibration bands of the free ligand and the complexes are in the region $4000-400 \mathrm{~cm}^{-1}$ $[15,16]$. The characteristic frequencies of the ligands and metal complexes are given in Table 5. In case of Lanso molecule the $\mathrm{N}-\mathrm{H}$ (aromatic sec. amine) stretching occurs at $3050 \mathrm{~cm}^{-1}$, whereas sulfoxide $(\mathrm{S}=\mathrm{O})$ stretching occurs at $1090 \mathrm{~cm}^{-1}$. The band of $\mathrm{C}=\mathrm{N}$ occurs at $1590 \mathrm{~cm}^{-1}$ [17]. In free cytosine molecule, the $\mathrm{C}-\mathrm{N}$ ring band is shown in $1276 \mathrm{~cm}^{-1}$ and $\mathrm{C}=\mathrm{O}$ is at $1700 \mathrm{~cm}^{-1}[18]$.

In case of ternary complexes of M-lansoprazole-cytosine, all the complexes showed frequency of $(\mathrm{N}-\mathrm{H})$ at $\sim 3050 \mathrm{~cm}^{-1}$ showing that there is no involvement $(\mathrm{N}-\mathrm{H})$ group in complex formation. The frequency of $(\mathrm{C}=\mathrm{N})$ bands appears at different region in complexes, that is, lowered by $\sim 40 \mathrm{~cm}^{-1}$ indicating the coordination of nitrogen atom of $(\mathrm{C}=\mathrm{N})$ with metal, whereas sulfoxide stretching shifts to lower frequencies at $\sim 50 / 60^{-1} \mathrm{~cm}$ due to coordination of the sulfonyl oxygen with metals in all the complexes. Thus, lansoprazole molecule chelates with metal ions using its $(\mathrm{C}=\mathrm{N})$ group and $(\mathrm{S}=\mathrm{O})$ group, acting as bidentate ligand.

The $\mathrm{C}=\mathrm{O}$ bonding of cytosine at $\sim 1700^{-1} \mathrm{~cm}$ shifts to lower frequency on coordination and change in $\mathrm{C}-\mathrm{N}$ ring is also reported. Hence in these complexes cytosine also acts as bidentate ligand coordinating through the nitrogen at $\mathrm{N}(3)$ and the oxygen of $\mathrm{C}=\mathrm{O}$. Additional bands in the complex in the region $740-765 \mathrm{~cm}^{-1}$ compared with IR spectra of free ligand have tentatively been assigned to $\mathrm{M}-\mathrm{O}$ frequency and new band appearing at $1380-1390 \mathrm{~cm}^{-1}$ in the complexes might be due to chelate ring formation in the complexes. The appearance of strong band at $\sim 820 \mathrm{~cm}^{-1}$ and $\sim 3380 \mathrm{~cm}^{-1}$ in the spectra of all the ternary complexes indicates the presence of coordinated water.

5.2. Mass Spectra. In the present investigations, the mass spectrum of the lansoprazole shows the formation of molecular ion peak at M/Z 344 corresponding to the total molecular weight of the ligand. Data on the molecular weight of complexes are present in table along with the values calculated on the basis of established molecular formulae of the complexes as shown in Table 6.

5.3. ${ }^{1} H$ NMR Spectra. To confirm the coordination of the ligands to the metal ion the complexes, ${ }^{1} \mathrm{H}$ NMR spectra were recorded for the ligands and its inner transition metal complexes. The important chemical shifts for the ligands and the complexes are given in the Table 7 . The ${ }^{1} \mathrm{H}$ NMR spectra of the ligand have the expected characteristic signals. The $\mathrm{CH}_{3}$ proton shows singlet at $\delta 2.16$ and $\mathrm{O}-\mathrm{CH}_{3}$ proton at $\delta 3.69 \mathrm{ppm}$ and the peak observed at $\delta 4.71$ is attributed to $\mathrm{CH}_{2}$ protons. In addition multiplet peak at $\delta 6.8-8.2$ may be due to aromatic protons and peak at $\delta 13.2$ is observed due to $\mathrm{NH}$ proton of benzimidazole ring.

In case of ternary complexes of lansoprazole-cytosine, the chemical shifts occur at low field; that is, deshielding of proton occurs in methylene group proving the involvement of electron of $\mathrm{S}=\mathrm{O}$ in bonding. Signals observed in the complexes at region of $\delta 8.18-8$ due to the azomethine proton have either remained unaffected or shifted slightly to higher field with reference to those of the parent ligand, and the 


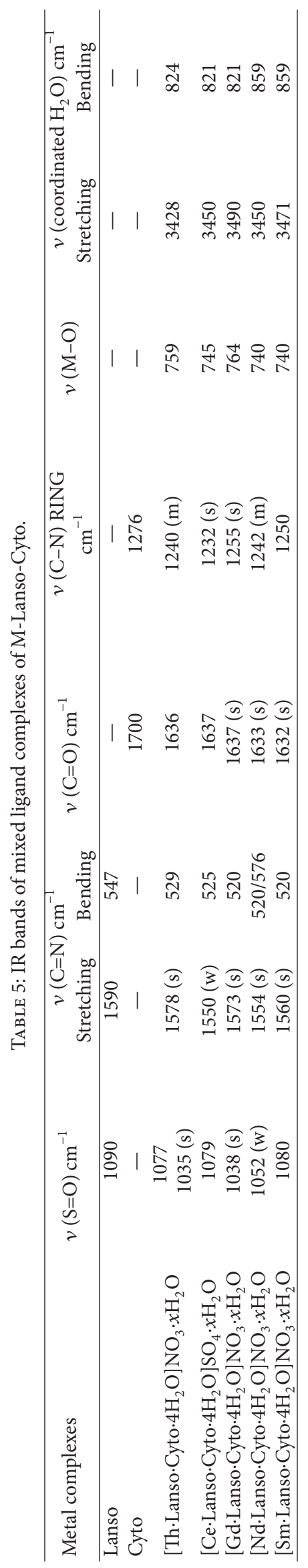


TABLE 6: Mass spectra of mixed ligand complexes of Lanso and Cyto.

\begin{tabular}{|c|c|c|}
\hline Metal complex & Structure & Spectral mass \\
\hline$\left[\right.$ Th. Lanso $\cdot$ Cyto $\left.\cdot 4 \mathrm{H}_{2} \mathrm{O}\right] \mathrm{NO}_{3} \cdot x \mathrm{H}_{2} \mathrm{O}$ & $1: 1: 1: 4 \mathrm{H}_{2} \mathrm{O}$ & 793 \\
\hline$\left[\right.$ Ce'Lanso $\cdot$ Cyto $\left.4 \mathrm{H}_{2} \mathrm{O}\right] \mathrm{SO}_{4} \cdot x \mathrm{H}_{2} \mathrm{O}$ & $1: 1: 1: 4 \mathrm{H}_{2} \mathrm{O}$ & 706 \\
\hline$\left[\mathrm{Gd} \cdot\right.$ Lanso.Cyto $\left.4 \mathrm{H}_{2} \mathrm{O}\right] \mathrm{NO}_{3} \cdot x \mathrm{H}_{2} \mathrm{O}$ & $1: 1: 1: 4 \mathrm{H}_{2} \mathrm{O}$ & 703 \\
\hline$\left[\mathrm{Nd} \cdot\right.$ Lanso $\cdot$ Cyto $\left.4 \mathrm{H}_{2} \mathrm{O}\right] \mathrm{NO}_{3} \cdot x \mathrm{H}_{2} \mathrm{O}$ & $1: 1: 1: 4 \mathrm{H}_{2} \mathrm{O}$ & 701 \\
\hline
\end{tabular}

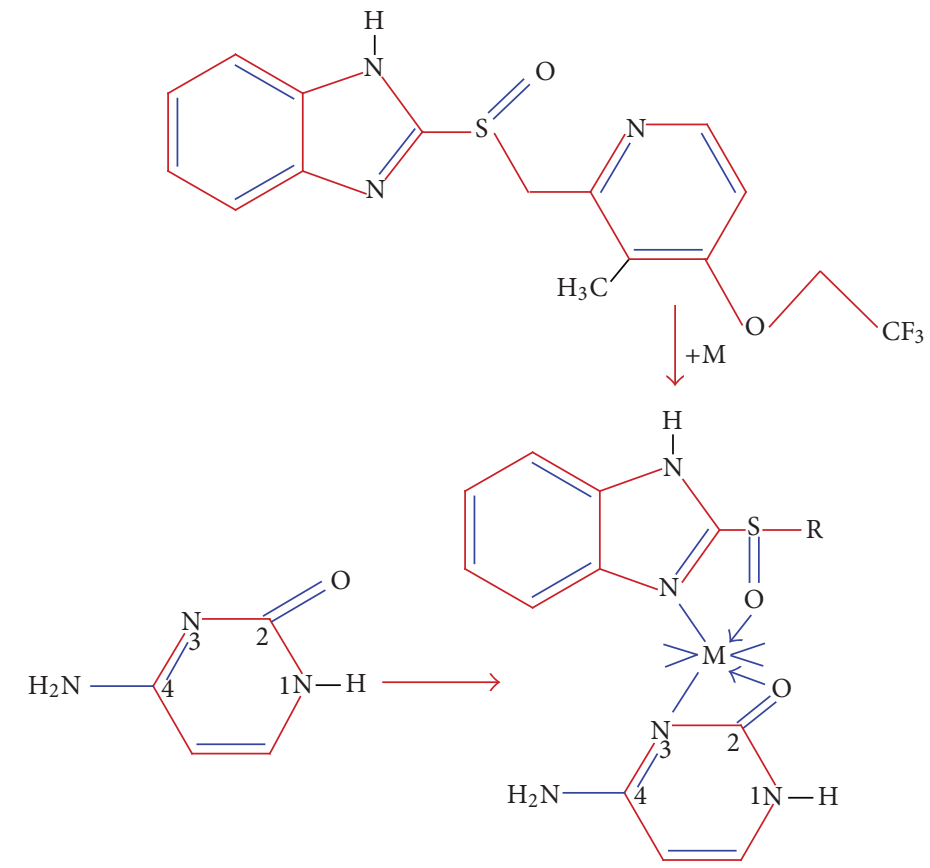

FIGURE 1: Proposed Scheme and Structure of representative ternary complex (M-Lanso-cyto).

position of signal due to $\mathrm{NH}$ proton remains unaffected in the complexes. Rest of the chemical shift is more or less the same in the ligands and their complexes. These observations support the assigned structure to the complex.

5.4. Electronic Spectra. Typical spectral data of the metal salts, ligand and ternary complexes of inner transition metal complexes have been investigated in ethyl alcohol and are shown in Tables 8(a) and 8(b). The electronic spectra of the lansoprazole display absorption bands at 219, 301 which is assigned to $n-\pi^{*}$ and $\pi-\pi^{*}$ transition, respectively. The electronic spectra of the complexes show a shift towards lower frequency. This shift was attributed to the effects of the crystal field upon the inter electronic repulsion between the 4 f electrons.

Some red shift or nephelauxetic effect is observed in the alcohol solutions of these complexes. This red shift is usually accepted as evidence of a higher degree of covalency than the presence of aqua compounds $[13,19]$. In all the complexes, marked enhancement in the intensity of the bond has been observed. This red shift of the hypersensitive bands has been utilized to calculate the nephelauxetic effect $(\beta)$ in these chelate complexes. From the $\beta$ values the covalence factors $\left(b^{1 / 2}\right)$, Sinha parameter $(\delta \%)$ (metal-ligand covalency percent), and the covalency angular overlap parameter $(\eta)$ have been calculated using the following expressions [20]:

$$
\begin{aligned}
b^{1 / 2} & =\frac{1}{2}\left[(1-\beta)^{1 / 2}\right], \\
\delta(\%) & =\left[\frac{(1-\beta)}{\beta}\right] \times 100, \\
\eta & =\left[\frac{(1-\beta)^{1 / 2}}{\beta^{1 / 2}}\right] .
\end{aligned}
$$

The positive values for $(1-\beta)$ and $\delta \%$ in these coordination compounds suggest that the bonding between metal and ligand is covalent compared with the bonding between the metal and an aqua ion. The values of parameter of bonding $\left(b^{1 / 2}\right)$ and angular overlap parameter $(\eta)$ were found to be positive, indicating covalent bonding. The mechanism of the formation and structure of representative ternary complex can be given in Figure 1.

\section{Antifungal Activity}

The antifungal activity of the ligand, metal salts and the corresponding complexes was assayed simultaneously against 


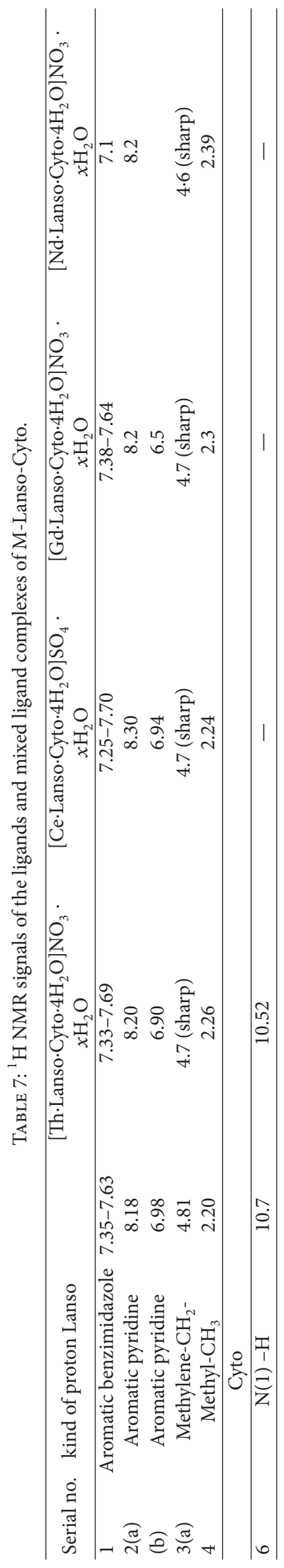




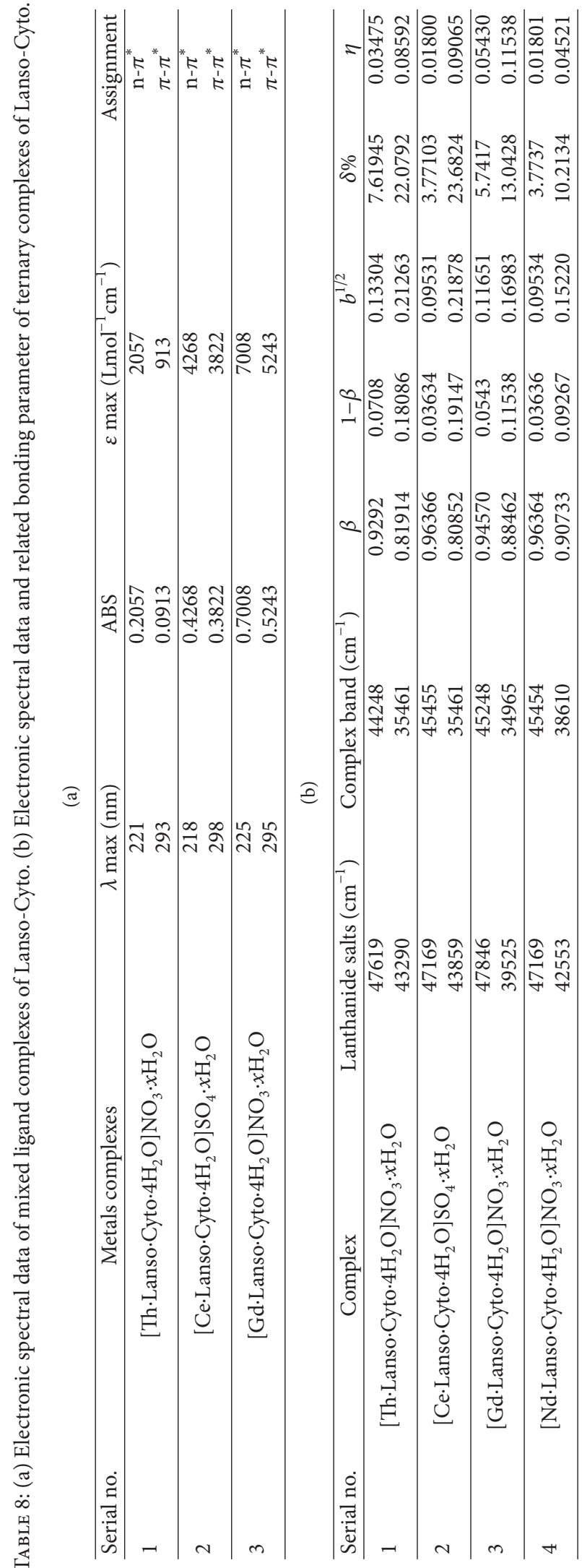


TABLE 9: Sensitivity test of lansoprazole, cytosine and their complexes against Aspergillus niger culture.

\begin{tabular}{lccccc}
\hline \multirow{2}{*}{ Serial no. } & & \multicolumn{4}{c}{ Inhibition Diameter $(\mathrm{cm})$} \\
& & Metal ion & Lanso & Cyto & M-Lanso-Cyto \\
\hline 1 & Th & 1.1 & 0.6 & 0.5 & 1.1 \\
2 & Ce & 0.7 & 0.6 & 0.5 & 1.3 \\
3 & Gd & 0.8 & 0.6 & 0.5 & 1.6 \\
\hline
\end{tabular}

Aspergillus niger fungusby paper disk method [21] at room temperature. The pure metal salts, and lansoprazole drug showed activity in Aspergillus niger. The zones of inhibition against microorganism were measured (in $\mathrm{cm}$ ) after 48 hours of incubation as shown in Table 9. The mixed ligand complexes showed higher inhibition zone as compared to parent drug.

\section{Conclusion}

The studied ternary complexes of inner transition metals showed 1:1:1 (M:LANSO:CYTO) composition as indicated from elemental analyser and exhibited corresponding conductivities suggesting 1:1:1 electrolytic behaviour. The IR data reveals that all the ligands function as bidentate ligands. Lansoprazole molecules chelate with the metal ions using their $\mathrm{C}=\mathrm{N}$ group and $\mathrm{S}=\mathrm{O}$ group and the cytosine acts as a chelating ligand binding through its $\mathrm{N}(3)$ and the oxygen of $\mathrm{C}=\mathrm{O}$. The ${ }^{1} \mathrm{H}$ NMR spectra of nonequivalent proton of lansoprazole in complex exhibit chemical shift towards lower field due to complexation with metals.

The complexes may be formulated $\left(\mathrm{L}_{\text {Lanso }} \cdot \mathrm{M} \cdot \mathrm{L}_{\text {cyto }} \cdot 4 \mathrm{H}_{2} 0\right)$ $\mathrm{X} \cdot n \mathrm{H}_{2} 0$ where $\mathrm{X}$ is $\mathrm{SO}_{4}{ }^{2-}$ or $\mathrm{NO}_{3}{ }^{2-}$. The result of antifungal activity indicates that the complexes are more active than free ligand (lansoprazole drug). The possible general structure of these representative ternary complexes is shown in Figure 1.

\section{Acknowledgments}

The authors are thankful to the Chemistry Department for providing all laboratory facilities. They are grateful to Mr. Chowdary of Nosch Labs, Hyderabad, for providing pure powdered lansoprazole. Director of CDRI Lucknow for mass spectrum, NMR, the elemental analysis is also acknowledged. authors are also thankful to the Director of MPCST Bhopal for providing UV spectra and antimicrobial study. Cali Labs for IR spectroscopy is also acknowledged.

\section{References}

[1] C. Picard, N. Geum, I. Nasso et al., "A dual lanthanide probe suitable for optical (Tb3+ luminescence) and magnetic resonance imaging (Gd3+ relaxometry)," Bioorganic and Medicinal Chemistry Letters, vol. 16, no. 20, pp. 5309-5312, 2006.

[2] S. Aime, S. G. Crich, E. Gianolio, G. B. Giovenzana, L. Tei, and E. Terreno, "High sensitivity lanthanide(III) based probes for MRmedical imaging," Coordination Chemistry Reviews, vol. 250, no. 11-12, pp. 1562-1579, 2006.
[3] R. Reisfeld and C. K. Jorgensen, Lasers and Excited states of Rare Earths, Springer, Berlin, Germany, 1977.

[4] S. J. Franklin, "Lanthanide-mediated DNA hydrolysis," Current Opinion in Chemical Biology, vol. 5, no. 2, pp. 201-208, 2001.

[5] J. Sluka, J. Navakand, and Z. Budesinsk, "2-Phenylbenzimidazoles as potential anthelminthics," Collection of Czechoslovak Chemical Communications, vol. 41, pp. 3628-3634, 1976.

[6] L. S. Welage and R. R. Berardi, "Evaluation of omeprazole, lansoprazole, pantoprazole, and rabeprazole in the treatment of acid-related diseases," Journal of the American Pharmaceutical Association, vol. 40, no. 1, pp. 52-62, 2000.

[7] J. P. Reilly, American Journal of Health-System Pharmacy, vol. 40, pp. 52-62, 2000.

[8] S. J. Spechler, "GERD and its complications," Mount Sinai Journal of Medicine, vol. 67, no. 2, pp. 106-111, 2000.

[9] A. Kwang-hyun, Bulletin of the Korean Chemical Society, vol. 23, p. 4, 2002.

[10] O. P. Agarwal, Chemistry of Organic Natural Products, vol. 2, 2008.

[11] M. V. Chidambaram and P. K. Bhattacharya, Journal of Inorganic and Nuclear Chemistry, vol. 39, p. 2471, 1970.

[12] H. Irving and H. S. Rossotti, Journal of the Chemical Society, p. 1176, 1955.

[13] C. K. Jørgensen, R. Pappalardo, and E. Ritterhaus, "Reflection spectra of lanthanides in thorium(iv) oxide and the large nephelauxetic effect of oxide ligands or vacancies," Zeitschrift fuer Naturforschung, vol. 19, pp. 424-433, 1964.

[14] E. Uusitalo, Ann. Acad. Sci. Tenn, vol. 87, p. 419, 1957.

[15] R. M. Silverstein, Spectrophotometric Identification of Organic Compounds, John Wiley, New York, NY, USA, 2009.

[16] J. R. Dyer, Application of Absorption Spectroscopy of Organic Compounds, Prentice Hall, 2009.

[17] G. G. Mohamed, F. A. Nour El-Dien, S. M. Khalil, and A. S. Mohammad, "Metal complexes of omeprazole. Preparation, spectroscopic and thermal characterization and biological activity," Journal of Coordination Chemistry, vol. 62, no. 4, pp. 645-654, 2009.

[18] A. R. Sarkar and S. Mandal, "Insulin mimetic peroxo complexes of vanadium containing uracil or cytosine as ligand," MetalBased Drugs, vol. 7, no. 3, pp. 157-164, 2000.

[19] S. P. Sinha, "Ternary lanthanide complexes of the type M(HSal)3(TBP)2: preparation and spectroscopic studies," Journal of Inorganic and Nuclear Chemistry, vol. 33, pp. 2205-2212, 1971.

[20] M. Mohan, J. P. Tandon, and N. S. Gupta, "Synthesis and characterization of some lanthanide(III) chelates with $\mathrm{O}$ hydroxyacetophenone oxime," Inorganica Chimica Acta, vol. 111, pp. 187-192, 1986.

[21] A. W. Bauer, W. M. M. Kirby, J. C. Sherris, and M. Truck, "Antibiotic susceptibility testing by a standardized single disk method," American Journal of Clinical Pathology, vol. 45, pp. 493-496, 1966. 

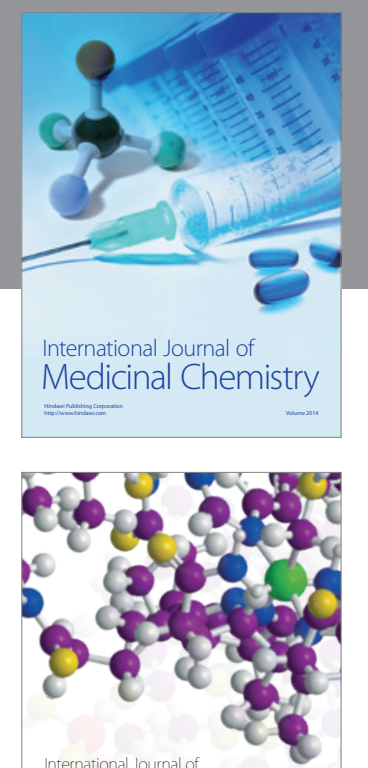

\section{Carbohydrate} Chemistry

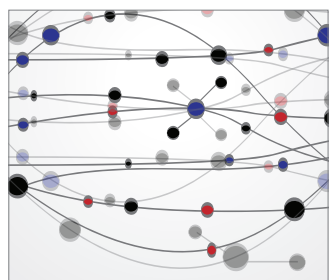

The Scientific World Journal
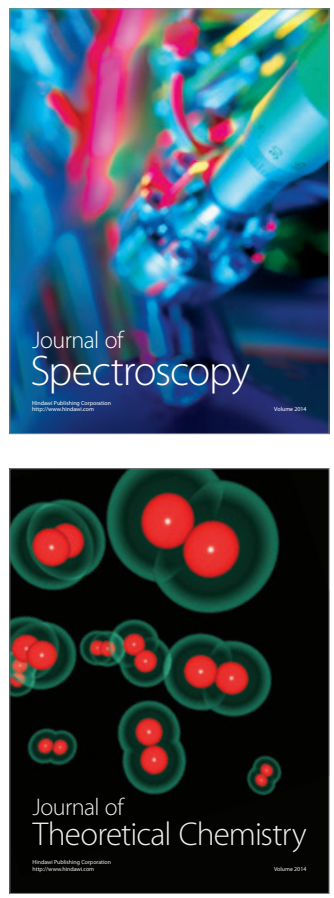
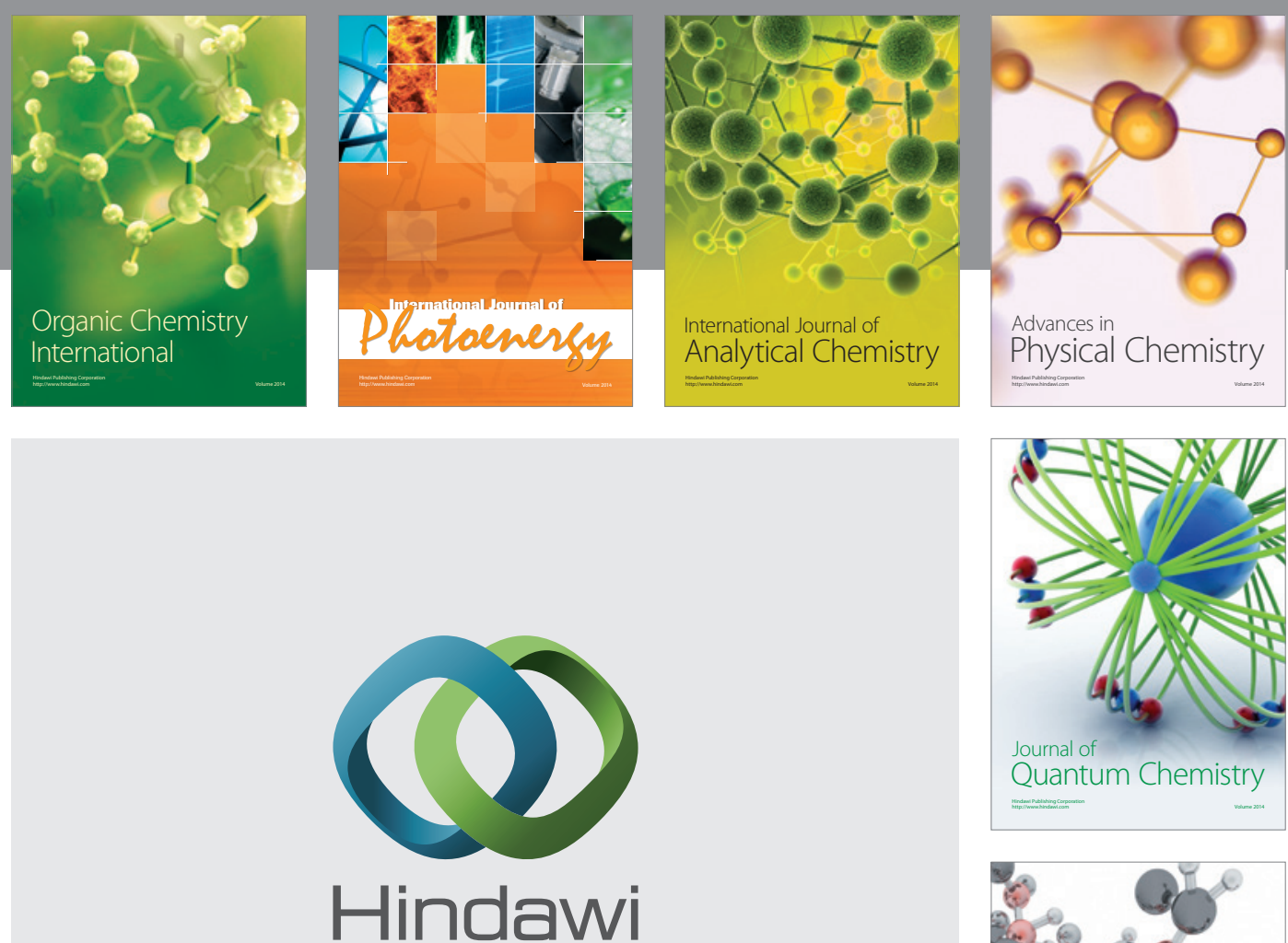

Submit your manuscripts at

http://www.hindawi.com

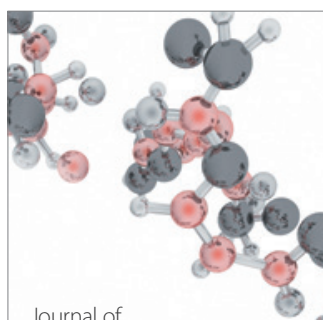

Analytical Methods

in Chemistry

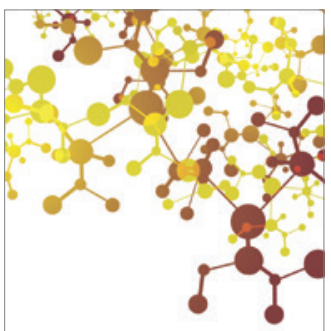

Journal of

Applied Chemistry

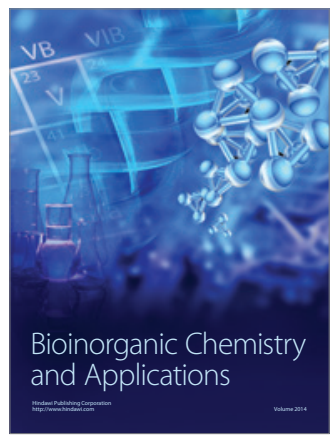

Inorganic Chemistry
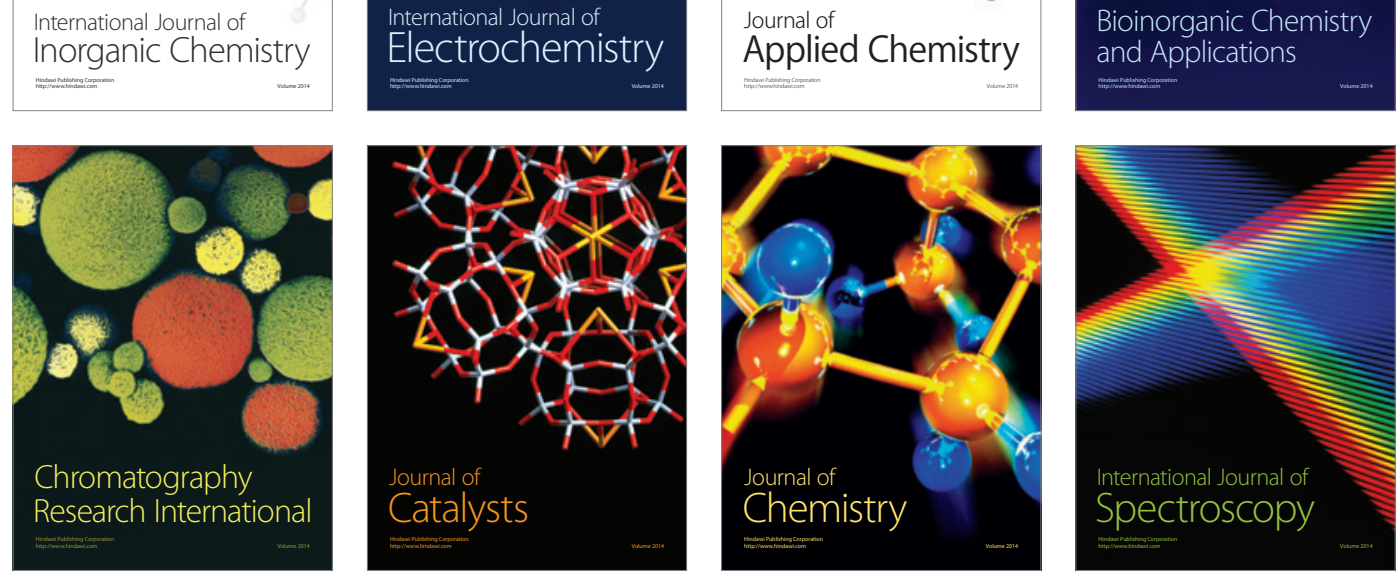